\title{
Enabling the IPBES conceptual framework to work across knowledge boundaries
}

\author{
Ria Dunkley ${ }^{1} \cdot$ Susan Baker ${ }^{2} \cdot$ Natasha Constant $^{3,4} \cdot$ Angelina Sanderson-Bellamy $^{3}$
}

Accepted: 15 September 2018 / Published online: 21 September 2018

(c) The Author(s) 2018

\begin{abstract}
The IPBES conceptual framework (CF) serves an instrumental value to translate usable knowledge into policy across spatial scales, alongside a normative function to engage diverse knowledge systems, promoting inclusivity and enhancing legitimacy. It has been argued that the CF operates as a boundary object, a communication and organisation tool for those working across diverse knowledge systems, designed to help them reach shared goals. The paper focuses on this claim, exploring the three core characteristics of a boundary object: interpretive flexibility, material and organisational structure, and the recognition of dissention. We suggest that too much emphasis is placed within the CF upon interpretive flexibility, whilst meeting information needs and the work requirements of all individuals, groups and communities who use the CF are overlooked. By forcing consensus, the IPBES $\mathrm{CF}$ ignores the critical dimensions of a boundary object. We argue that embracing the full characteristics of a boundary object will enable the IPBES to support knowledge coproduction and translation across the knowledge systems, better achieving its goal of providing policy advice.
\end{abstract}

Keywords Boundary object · Indigenous and local knowledge · Diverse knowledge systems $\cdot$ Coproduction $\cdot$ Science: policy interface

\section{Introduction}

The Intergovernmental science-policy platform on biodiversity and ecosystem services (IPBES) was established in 2012 under the auspices of the United Nations, with a remit to act as an independent agent to assess the state of biodiversity and of the ecosystem services

Ria Dunkley

ria.dunkley@glasgow.ac.uk

School of Education, College of Social Sciences, University of Glasgow, Glasgow, UK

2 Cardiff School of Social Sciences and Sustainable Places Research Institute, Cardiff University, Cardiff, UK

3 Sustainable Places Research Institute, Cardiff University, Cardiff, UK

4 South African Research Chair on Biodiversity and Value change, School of Mathematical and Natural Sciences, University of Venda, Private Bag X5050, Thohoyandou 0950, South Africa 
it provides to society. More specifically, the Platform is expected to strengthen the scientific foundations for policy making for the purposes of conservation and sustainable use of biodiversity, long-term human well-being, and the promotion of sustainable development (UNEP 2010). The work of the IPBES has been specified in the so-called Busan Outcomes, which were agreed at an ad hoc intergovernmental and multi-stakeholder meeting in the Republic of Korea, in 2010:

1. Respond to requests from Governments, including those conveyed to it by multilateral environmental agreements related to biodiversity and ecosystem services. Account should be taken, as appropriate, of inputs and suggestions made by relevant stakeholders, such as other intergovernmental organisations, international and regional scientific organisations, environment trust funds, non-governmental organisations and the private sector.

2. Identify and prioritise key scientific information needed for policymakers at appropriate scales and catalyse efforts to generate new knowledge by engaging in dialogue with key scientific organisations, policymakers and funding organisations.

3. Perform regular and timely assessments of knowledge on biodiversity and ecosystem services and their inter-linkages, which should include comprehensive global, regional and, as necessary, sub-regional assessments and thematic issues at appropriate scales and new topics identified by science and as decided upon by the plenary. These assessments must be scientifically credible, independent and peer-reviewed, and must identify uncertainties. There should be a clear and transparent process for sharing and incorporating relevant data.

4. Support policy formulation and implementation by identifying policy-relevant tools and methodologies and, where necessary, to promote and catalyse their further development.

5. Prioritise key capacity building needs to improve the science-policy interface and catalyse financing for such capacity building activities by providing a forum with conventional and potential sources of funding (UNEP 2010).

Communications and outreach work is expected to help realise the societal impact of their work (IPBES 2012). In undertaking its work, the Platform is required to recognise and respect the contribution of indigenous and local knowledge to the conservation and sustainable use of biodiversity and ecosystems (IPBES 2014). Eventually, a set of Procedures for Working with Indigenous and Local Knowledge Systems was approved at IPBES4, 2016 (IPBES/4/L.6). These procedures followed from work undertaken by a Task Force on indigenous and local knowledge (ILK) that was established to address how the IPBES could engage with different knowledge systems. However, despite recognising that the knowledge held by indigenous peoples is of central relevance to their goals, the rigidity, formality and institutional requirements of IPBES processes are not easily conducive to including ILK holders or their knowledge systems (UNESCO 2013, p. 76; Obermeister 2017; see Baker (2018) for a more detailed critique).

With such a wide remit and array of tasks, the IPBES has developed a conceptual framework (CF) to describe 'a concise summary in words or pictures of relationships between people and nature' (Díaz et al. 2015a). The aim is to ensure 'coherence and coordination between the Platform's functions' (Vohland and Nadim 2015). The need for such coherence may in part be linked to ongoing concerns that the convention on biological diversity (CBD) is itself marked by too wide a scope and ambition, with lack of focus and resultant effectiveness (Baker 2016). The creation of a formal ontology through a CF aims at 
providing knowledge representation that is not only seen to be unambiguous, but adaptable, sharable and reusable (Katsumi et al. 2016). Thus, according to those that devised the $\mathrm{CF}$, it can support their work because it provides 'a shared language and a common set of relationships and definitions to make complex systems as simple as they need to be for their intended purpose' (Díaz et al. 2015b). A CF encodes a standard terminology, common set of premises, and agreed causal relationships. Whilst the encoding remains invariant across scale, the context of IPBES assessments changes, so the CF aims to provide the IPBES with an analytical tool to ensure comparability across different spatial scales. Such comparability is essential to the IPBES, given that it is expected to produce assessments across both regional and global levels to support inter- and intragovernmental policy actions. The presentation of a clear, unified set of assessments, applicable at regional level, yet comparable across scale will, it is argued, support efforts to tackle biodiversity and ecosystem services loss and help 'to catalyse a positive transformation' (http://www.ipbes.net/ conceptual-framework).

Whilst strongly driven by an instrumental rationale, the inclusion of different knowledge systems and a diverse range of participants is also motivated by recognition that broad inclusion will lend legitimacy to the IPBES work (Heubach and Lambini 2018; Löfmarck and Lidskog 2017; Montana 2017; Tengö et al. 2014; Timpte et al. 2018). Legitimacy is closely tied to perceptions of procedural fairness and equitable participation (Baker and Chapin 2018). The need to account for the rights and agency of indigenous and local people has been raised in the CBD, encouraging new approaches to knowledge production and greater inclusivity and engagement of social actors in the global environmental assessments of biodiversity (Reimerson 2013; Montana 2017). Therefore, the CF also fulfils a more complex purpose to connect the 'different knowledge and value systems' (Opgenoorth et al. 2014) of those to whom the Platform reports internationally. This normative rationale involves the IPBES in the task of representing those that hold an episteme or values that differ from the dominant western, scientific framework. As such, the CF specifically seeks to represent both ILK and western scientific systems to inform regional and international biodiversity assessments and decision-making. Here, ILK is defined as a 'cumulative body of knowledge, practice, and belief, evolving by adaptive processes and handed down through generations by cultural transmission, about the relationship of living things (including humans) with one another and with their environment' (Díaz et al. 2015a). According to the IPBES, the CF serves as a conduit through which diverse knowledge and values systems can be drawn into the production of 'integrative, cross-paradigm, coproduced knowledge' (Díaz et al. 2015b). It will, it is argued, enable the IPBES to present a multi-evidence approach in its assessment and other work (Vohland and Nadim 2015). Indeed, the IPBES goes so far as to argue that 'the CF goes further than any previous initiative in the international environmental science-policy interface in its explicit, formal incorporation of knowledge systems other than western science... [representing an]...unprecedented effort towards cross-cultural and cross-disciplinary communicability' (Soberón and Peterson 2015). The CF of the IPBES therefore serves two dual functions: firstly, it has instrumental value, designed to generate 'usable' knowledge for policy making across different spatial scales (Díaz et al. 2015a, b). This also includes aiding the diffusion and uptake of knowledge (Wyborn 2015). Secondly, it serves a normative function, facilitating the engagement of different knowledge holders and the incorporation of their diverse knowledge systems, thereby responding to increasing calls for environmental governance processes to promote inclusivity and enhance their legitimacy (Beck et al. 2014; Koetz et al. 2012). The normative functioning of the CF therefore fulfils an instrumental function, via the explicit promotion of inclusion and legitimacy of divergent knowledge 
systems. This may be based upon a desire to make the IPBES' knowledge assessments appear uncontested and thus usable for policymakers (Figs. 1, 2).

However, there is nothing straightforward about the representation of ILK within the IPBES CF, nor in its attempts to synthesise diverse knowledge systems into a coherent scientific and policy message. On the contrary, the CF was the outcome of considerable contestation. Far from being a unified conceptualisation, numerous scholars have suggested that the $\mathrm{CF}$ is better understood as a 'boundary object', designed to reorientate the boundaries between knowledge systems (Borie and Hulme 2015; Löfmarck and Lidskog 2017; Bridgewater 2017). Boundary objects can support cross-boundary communication and knowledge translation by connecting those operating in different social worlds, whilst preserving their autonomy, (Rödder 2017). The IPBES, it is claimed, provides a rich case for studying attempts to operate across boundaries of knowledge systems (Löfmarck and Lidskog 2017; Thaman et al. 2013; Rathwell et al. 2015). The development of a boundary object is important in cross-cultural work, such as that of the IPBES, where processes of knowledge generation are based on different epistemologies and where there is an absence of shared means to validate knowledge claims (Natcher et al. 2005; Maclean 2015).

This paper further investigates this claim, examining the functioning of the $\mathrm{CF}$ and its efforts to bridge different knowledge systems, to determine whether it fulfils the conditions of being a boundary object. Through a critical examination of a boundary object, the authors argue that in order to achieve its functions, the CF must fulfil the three criteria set in the original conceptualisation by Star and Griesemer (1989). The material for analysis in this paper was collected by reviewing the literature written in response to the publication of the IPBES CF. This process involved an initial search of literature concerning the objectives of the $\mathrm{CF}$, the development of the framework, as well as critiques on the processes involved. Following independent reviews of all literature uncovered, the authors met to

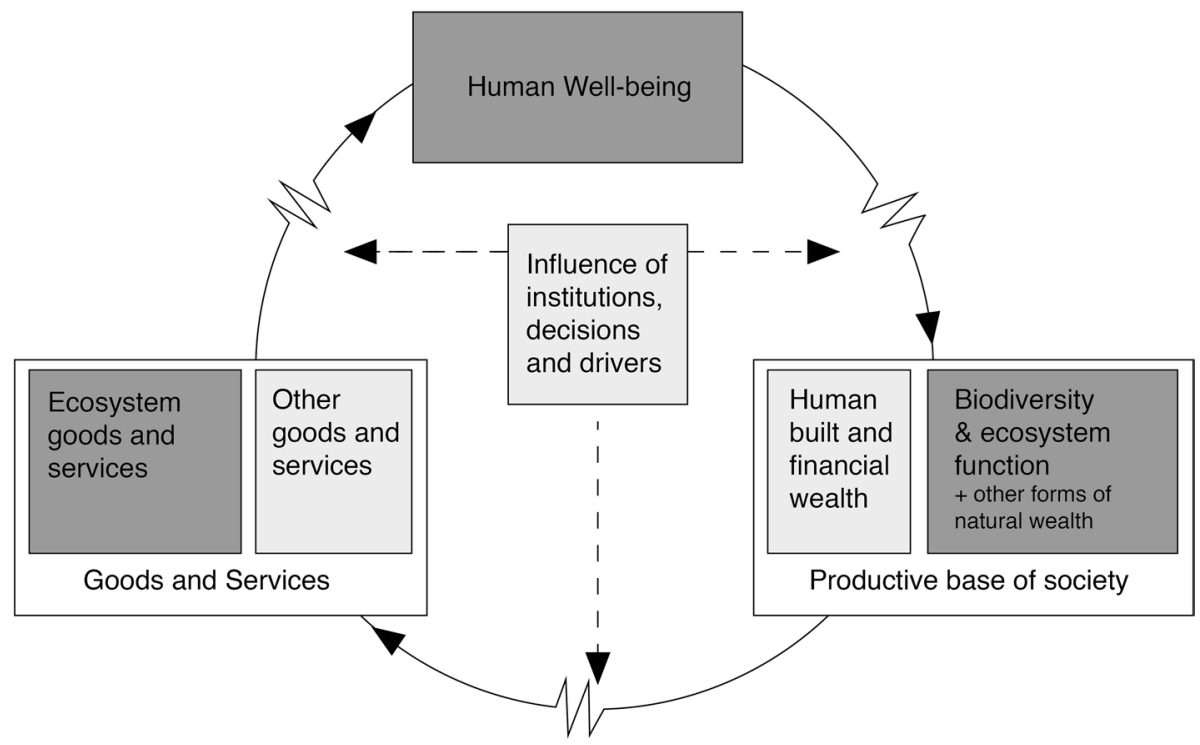

Fig. 1 First conceptual diagram, Paris workshop 2012. Building blocks are shown in square boxes. Interlinkages are indicated by the black arrows. Institutions, decisions and drivers influence and are influenced by the inter-linkages amongst the key building blocks, as indicated by the dashed arrows and zigzags (UNEP 2012) 


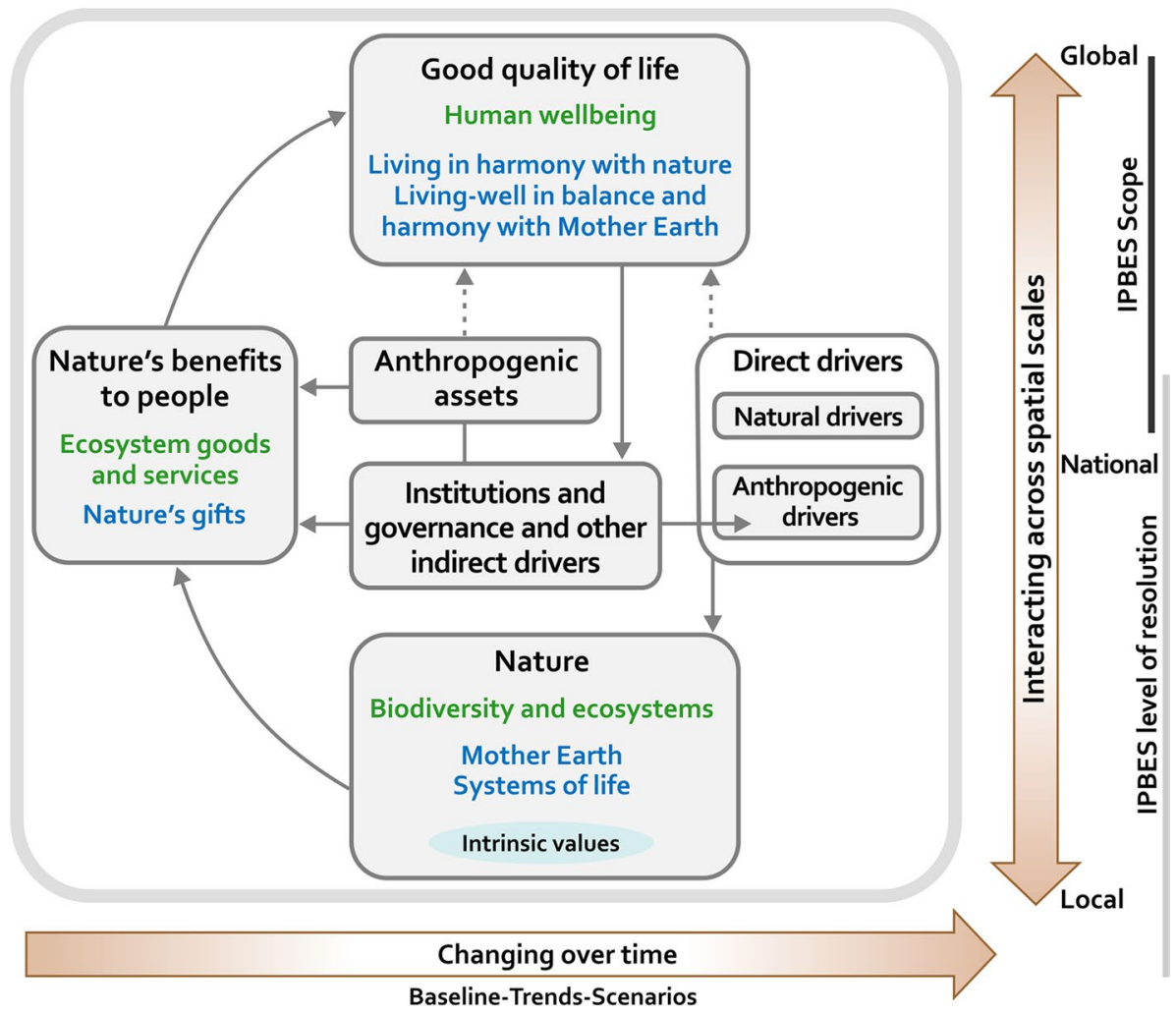

Fig. 2 The IPBES conceptual framework. Conceptual framework of the intergovernmental platform on biodiversity and ecosystem. In the central panel, delimited in grey, boxes and arrows denote the elements of nature and society that are the focus of the Platform. In each of the boxes, the headlines in black are inclusive categories that should be intelligible and relevant to all stakeholders involved in IPBES and embrace the categories of western science (in green) and equivalent or similar categories according to other knowledge systems (in blue) (IPBES 2013a)

discuss the main emergent themes from this body of knowledge before beginning the analysis process, which resulted in the synthesis presented herein. The authors complemented this with a review of the literature on the nature and use of boundary objects and their role in bridging knowledge systems. The paper also draws upon original material from the IPBES itself, either available online at their website, or in published formats, including in scientific journal and through the United Nations.

The efforts of the IPBES to promote collaborations across knowledge systems can help develop a better understanding of the challenges involved in knowledge coproduction (Johnson et al. 2016). There are, at a minimum, methodological challenges faced by those seeking to engage with epistemological differences and contestations regarding concepts of nature and diverging perspectives on knowledge validation (Vadrot et al. 2018). There are also ethical issues, such as how the distribution of power shapes responses to both the practical and philosophical challenges involved, and how power shapes knowledge generation and validation (Cornell et al. 2013; Díaz et al. 2015a). Yet, expectations are high, especially given that the IPBES has specifically committed itself to this task and has placed considerable emphasis on stakeholder participation and knowledge inclusion 
(Beck et al. 2014; Vohland et al. 2011), which differentiates it from its sister organisation, the IPCC. As an international epistemic community, there are expectations that it ought to incorporate different conceptual schemes and worldviews-especially given that the imperative to include the perspective not just of scientific experts but also of lay people is well established in biodiversity management (Jetzkowitz et al. 2017) and in the governance of the global commons (Rathwell et al. 2015). How the IPBES engages with this task holds important lessons for global environmental governance beyond those connected to the CBD regime. It can provide insight into international efforts to transform knowledge production and the overall framing of environmental challenges (Löfmarck and Lidskog 2017). This is important given the growing dissatisfaction at the international level with historical practices that privilege western forms of scientific knowledge at the expense of other forms, and reinforce a divide between different knowledge systems (Turnhout et al. 2012).

In seeking a way forward beyond mere critique of the CF of the IPBES, this article explores how the CF can better serve as a boundary object and details the advantages that this will bring to the IPBES' work. We argue that if the IPBES drew upon the full characteristics of its CF as a boundary object this would support the realisation of both its instrumental and normative functions.

\section{Exploring the concept of a boundary object}

Boundary work is used in various contexts to articulate the relationship between science and non-science, different languages, goals and epistemologies across the science-policy interface. Boundary work has traditionally focused on the objects (Star and Griesemer 1989), organisations (Guston 2001) and practices (Cash et al. 2003) that blur the boundaries between science and policy. Earlier research on the role of boundary work has concentrated on critiques of the assumptions, categories, and the epistemic authority of scientific knowledge (Gieryn 1983). This body of research demonstrates how autonomy building through rhetoric can delineate boundaries according to the boundary worker's aspirations (Gieryn 1983). In contrast, Star and Griesemer (1989) introduce the concept of boundary objects to emphasise how boundary objects serve to connect different social worlds. The initial discussion of boundary objects by Star and Griesemer (1989) perceived boundary objects as artefacts, as material objects illustrated as museum specimens and maps, which can embody different meanings according to the interpretations of different user groups. However, a boundary object can also be an analytical concept, and has been heavily applied, for example to the concepts of 'resilience' (Baggio et al. 2015; Brand et al. 2007) and 'ecosystem services' (Abson et al. 2014; see Trompette and Vinck (2009) for a review). A boundary object is shared by different communities, but viewed or used differently by each of them-whilst at the same time allowing for coordination of these different groups seeking consensus on aims and interests. Their importance lies in that they can transcend core differences in interpretation for functional reasons, often associated with the performance of particular work or meeting particular objectives, allowing for cooperation without consensus (Baggio et al. 2015). A boundary object, in short, links different communities of practice to enable them to collaborate (Wenger 1998), without necessarily having common consent or accord.

As an analytical concept, boundary objects function as 'scientific objects' that have different meanings in different social worlds, yet their structure is common enough to 
more than one world to make them recognisable (Star and Griesemer 1989). Such concepts are 'plastic enough to adapt to local needs and the constraints of several parties employing them, yet robust enough to maintain a common identity across sites' (Star 2010: 393). Furthermore, 'their boundary nature is reflected by the fact that they are simultaneously concrete and abstract, specific and general, conventional and customised' (Star 2010: 408). A 'many to many model' (p. 390) is used to identify boundary objects. This means that rather than having the concerns of several actors funnelled into one point of view, what is referred to as 'one passage point' — usually held by a manager, entrepreneur, or scientist—boundary objects enable several obligatory points of passage to be negotiated between different actors (Star 2010: 390). Star and Griesemer (1989) argue that the first job in creating a boundary object is to identify the passage points. The second job is to defend them. Boundary objects are thus created at the intersection of participating social worlds' (p. 396). A boundary is a dynamic concept allowing for movement from a generalised ill-structured form to locally tailored applications of a particular idea or concept (Star 2010). The ability of a boundary to 'tack and forth' between social worlds allows it to simultaneously exist in a specific state for different people whilst being universally vague across all social groups. Therefore, a boundary object can support collaboration by taking on diverse meanings without enforcing a singular approach, allowing different groups to work together (Star 2010).

Three characteristics define a boundary object, which when combined, allow it to be able to function across multiple actors: interpretative flexibility, material and organisational structure, and dissention. First, interpretative flexibility is required, where the boundary object can satisfy the needs of different user groups operating from different social worlds, whilst allowing communication between them (Star and Griesemer 1989). Interpretive flexibility is a core characteristic of a boundary object, so much so that Star (2010) later states that 'boundary objects became almost synonymous with interpretative flexibility' (p. 602). Through its focus upon interpretive flexibility, a boundary object can be read as primarily concerned with translation of knowledge systems (Star and Griesemer 1989). Interpretive flexibility is a crucial factor in translation in that it allows boundary objects to simultaneously accommodate local needs and the constraints of different actors, but also ensures that the structure of a boundary object is applicable to more than one social world, whilst also lending analytical coherence to its investigation. However, there is a risk that one paradigm assumes epistemic primacy over others (Star 2010; Star and Griesemer 1989). This can happen despite efforts to ensure that the various viewpoints of actors are represented. Star and Griesemer (1989) argue that there are an indefinite number of ways that actors from each cooperating social world may make their own world an obligatory passage point for the whole network of participants.

Including diverse knowledge systems is challenging and characterised by a lack of understanding and tensions that arise from differing views of what constitutes credible, salient, and legitimate knowledge (Cash et al. 2003). Having interpretative flexibility can allow a concept to satisfy the needs of multiple social groups (natural scientists, social scientists, policy makers, indigenous and local knowledge holders) and allow communication, whilst guarding its functional integrity, contributing knowledge systems based on different epistemologies to the policy community. However, boundary objects also need to meet the information needs and work requirements of all individuals, groups and communities who use it. In essence, a boundary object must be used between groups without compromising one social perspective over another (Star and Griesemer 1989). This brings us to the second principle of a boundary object, namely material and organisational structure. 
To reflect upon this, it is necessary to investigate more fully what 'boundary' means in this context. Star (2010) conceptualises the boundary as a shared space that emerges through the process of work, where different worlds work together (Star and Griesemer 1989). The boundary object inhabits these different worlds simultaneously yet must meet the demands of each (Star and Griesemer 1989). In the context of natural history work, for example, boundary objects are produced when sponsors, theorists and amateurs collaborate to produce representations of nature (Star and Griesemer 1989). This creates a boundary object that meets the information needs and working requirements of those that wish to cooperate (Star 2010). Thus, they must function as scientific objects that inhabit several intersecting social worlds and satisfy the information requirements and concerns of each (Star and Griesemer 1989). This process is dynamic, and 'objects form the boundaries between groups through flexibility and shared structure - they are the stuff of action' (Star 2010: 603). Crucially, a boundary object must not only be created through deliberation amongst diverse actors, but it must also be used between groups (Star 2010).

Boundary objects represent changing entities that are dynamic or created over a lifecycle, often transiting from their initial vagueness and flexibility towards a process of standardisation that allow information to be transferred effectively across social worlds and scales (Steger et al. 2018). However, there is no guarantee that epistemologically respectful practices will emerge from collaboration, particularly when standards vary between different socio-political contexts, disciplinary perspectives and knowledge systems, and where power dynamics influence the production of knowledge (Brand et al. 2007; Tengö et al. 2014; Castree 1995). Such tensions point to the need to develop equitable and transparent ways to share knowledge and to meet the information requirements of different user groups. Developing these raises, in turn, issues about the legitimacy and ethical dimensions of knowledge translation and coproduction that is commonly associated with boundary work.

Thirdly, a boundary object acknowledges that actors cooperate without consensus, where they tack 'back-and-forth' between their divergent understandings of that object (Star and Griesemer 1989). Whilst boundary objects can promote cooperation around common terminology, language or ideas, there is also an inherent tension between divergent viewpoints and perspectives held between different social groups. Star (2010) argues that the acknowledgement of dissention is the most often ignored characteristic of boundary objects. She states that it has become common practice to assume that achieving consensus is a crucial part of collaborative scientific work. She reflects upon the zeitgeist in the 1980 's to seek consensus in decision-making processes, thus misinterpreting the appropriate application of the boundary object concept. Yet, in observing various instances of the employment of boundary objects within scientific work, Star (2010) recognised that consensus was not always necessary. On the contrary, amongst the situations she observed, 'consensus was rarely reached and fragile when it was, but cooperation continued, often unproblematically’ (p. 604). When boundary objects are used in practice, actors negotiate their different standpoints and collaborate in spite of them. In this practice, Star (2010) suggests, actors interpret the boundary object in alternative ways.

A key rationale for the development of the IPBES CF has been the ambition to achieve a 'greater unity to biodiversity knowledge', with the CF designed to integrate diverse participants and knowledge systems, itself achieved through consensus-based decision-making processes (Montana 2017, p. 20). However, we point to the fact that the development of the IPBES CF has been surrounded by conflicts, as discussed below, so as to be mindful that knowledge creation does not necessarily emerge out of knowledge unity (Star and Griesemer 1989). Recognition of dissention across knowledge systems brings competing 
interests, needs, perspectives, worldviews, and moral frames to the fore, especially in the context of asymmetries of power and rights (Maclean 2015). Much of the literature advocates for the need to overcome power imbalances, and points to the importance of developing supportive, transparent mechanisms to bridge knowledge systems so that it generates usable and diverse forms of knowledge to inform the science-policy interface (Cash et al. 2003, 2006; Guston 2001). Power imbalances emerge when a subset of actors force an artificial consensus that fails to reflect the perspectives of all actors. These three characteristics of a boundary object namely, interpretive flexibility; material and organisational structure; and the recognition of dissention help to identify an important set of processes that can improve the capacity of the IPBES CF to meet its instrumental and normative objectives. The next section will describe in detail the three core characteristics of a boundary object, as they apply to the IPBES CF, and analysing whether the CF meets these requirements.

\section{The IPBES conceptual framework as a boundary object}

\subsection{Interpretative flexibility}

Interpretative flexibility is important if the IPBES' CF is to serve as a translation device and facilitate communication across different knowledge systems. Thus, the CF must allow for a common framing to meet the concerns of different groups to ensure collaboration across the boundary. Here, boundaries exist between natural and social scientists, between science and policy makers and between holders of scientific knowledge and ILK. Although these boundaries can serve to maintain the integrity of a knowledge type, boundaries can also act as barriers to communication, knowledge synthesis and translating knowledge to action (Maclean 2015). Understanding the context and different interpretations of the IPBES CF can also support dialogue across the boundary between different social groups and knowledge systems (Star 2010).

The integration of different knowledge types in the IPBES CF was surrounded by considerable contestations, including during a workshop held in Paris in 2012, which was organised by UNESCO on behalf of UNEP and the Interim IPBES Secretariat. In setting out the modalities and institutional arrangements for IPBES, the UNEP believed that a CF would be an essential tool to guide the development of the work programme of IPBES. As a result, an invited group of experts drawn from those working as scientists and within academia, were charged with the task of drafting the IPBES CF at the Paris Workshop (Vadrot 2016). It was expected that the CF would set out the key components and interactions of the complex social-ecological systems that the IPBES was to research, develop a joint understanding of their key elements, and support agreement on common definitions and approaches to guide assessment activities and associated IPBES objectives. By providing common terminology and concepts, the CF was also seen as critical for facilitating and strengthening multidisciplinary collaboration and enabling communication across disciplines (UNEP 2012). The Paris meeting resulted in a CF designed to fulfil these various expectations.

However, a delegation from Bolivia attending the Paris meeting rejected this framework, arguing that it represented dominant, Western scientific visions of biodiversity perceived through the notion of ecosystem services (Borie and Hulme 2015). Bolivian delegates emphasised that the CF should include cultural, spiritual and political elements, and respect human rights as well as the rights of Mother Earth. They further cautioned against 
the commercialisation of biodiversity (IISD Reporting Services 2013), which could follow from overemphasis on ecosystem services provided for humankind. The Bolivia delegation advocated an alternative framework based on an ideal of living well, in balance and harmony with Mother Earth. The Bolivian critique highlighted the importance of ILK as an alternative knowledge system which did not fall into the ecosystem services paradigm presented in the draft CF (Borie and Hulme 2015). Others questioned the utilitarian view of nature that underpinned the draft CF (Vadrot 2016) and its links to the commodification of nature. In contrast, those advocating an emphasis on ecosystem service argued that this would help ensure 'epistemic consistency' with other biodiversity assessments, such as the seminal Millennium Ecosystem Assessment, and be a pragmatic way to present biodiversity issues to policy makers (Borie and Hulme 2015). They also perceived the Bolivia Critique as an assertion of a political agenda (Borie and Hulme 2015).

Because of this dispute, the draft CF that emerged from the Paris Workshop was not considered adequate. The need to develop an alternative CF, which included ILK, diverse conceptualisations of the relationships between human and non-human beings, and other visions of well-being was acknowledged. This inclusion was also seen as essential for arriving at a better understanding of the complex interrelationships amongst biodiversity, ecosystem services and human well-being, as complementary to science-based frameworks, and as reinforcing the delivery of IPBES objectives (IPBES 2013b). There was also a clear message from those hosting the event that the $\mathrm{CF}$ 'would benefit from being developed through an open, deliberative and transparent process including scientific experts, indigenous and local knowledge experts, policymakers and other relevant stakeholders' (UNEP 2012). Nonetheless, there remained agreement on the importance of developing a single unifying CF for the IPBES, as a useful tool to clarify and focus thinking about complex relationships and to support communication across disciplines, knowledge systems and between science and policy, in short to act as a boundary object. It was also seen as essential to help structure and prioritise work agendas and in ensuring clear messages to policy makers (UNEP 2012). The delivery of this unified CF would signal a working understanding amongst different stakeholders on how to assess and approach issues of biodiversity and ecosystem services in the IPBES assessment and other tasks (Thaman et al. 2013). This is important because the credibility of a science-policy interface can be judged by how effectively the 'stitching together [of] multiple knowledge systems that encompass divergent paradigms' occurs (Miller and Erickson 2006).

The final CF emerged from a meeting of the Multidisciplinary Expert Panel of the IPBES with other invited experts held in Cape Town, South Africa in August 2013, which has since been officially adopted by the IPBES (IPBES 2013a).

A colour code is used by the IPBES to distinguish two paradigms within the CF, the western scientific worldview and that representing ILK. Green is used to represent the view of actors using western concepts of ecosystem services, represented as Biodiversity and Ecosystem, Ecosystem Goods and Services, and Human Well-Being; and blue is used to represent the view of indigenous and local groups using the concepts of Mother Earth, Systems of Life, Natures Gifts, and Living in Harmony with Nature (Díaz et al. 2015a). By bringing these two world views together, the CF is designed to act as a 'stabilising device' between different knowledge systems (Borie and Hulme 2015). The employment of a Rosetta Stone metaphor, a rock inscribed with similar versions of a decree in three languages and used to decode Egyptian hieroglyphs, by Diaz et al. (Díaz et al. 2015a) to describe the new CF reinforces this focus upon translation and meaningful communication.

Whilst the new CF claims to recognise the legitimacy of both perspectives, it continues to be criticised. The two knowledge systems that the CF attempts to reconcile 
belong to heterogeneous and often oppositional social worlds. Scholars have highlighted the epistemological differences and power inequalities between different knowledge systems and argue that this continues to be represented in the new CF (Tengö et al. 2014). Thus, it is claimed that the $\mathrm{CF}$ 'tends to marginalise those forms of knowledge that cannot easily be translated into the ecosystem services approach' (Borie and Hulme 2015). Borie and Hulme (2015) bring attention to the main translation device, the colour coding, used to distinguish between paradigms. This is why some argue (see Turnbull 2000) for the development of an additional third space, created through deliberation and negotiation between different worldviews. In this third space, the idea of a single rationality is abandoned, and multiple rationalities are allowed to exist. The power and antagonism of different rationalities are acknowledged, in contrast to denying, erasing or suppressing other ways of knowing.

The explicit depiction of only two knowledge systems within the CF is also problematic. The symbolic merging of knowledge paradigms can be seen to reduce knowledge concerning biodiversity and ecosystem services as belonging either to science or as being 'other'. This essentialises the distinction between science and ILK (Borie and Hulme 2015: 494). Both forms of knowledge are thus typecast. On the one hand, the 'Mother Earth system', as it is presented, romanticises and idealises an 'other', closed and stable ILK system. This vision of ILK appears, at least in part, to be reliant upon early colonial sources describing indigenous populations (Díaz et al. 2015b). On the other hand, the CF frames (Western) science as wholly conditioned by an ecosystem services approach, despite the fact that this approach is also contested. The focus upon human needs, to the detriment of other life forms, is seen by critics as attributing only instrumental value to nature and as misrepresenting the complexity of human-nature relationships, turning nature into a consumptive commodity (Schröter et al. 2014; Jetzkowitz et al. 2017). Furthermore, the inclusion of a small percentage of social scientists in the IPBES process fails to account for the heterogeneity present within the social science community, and for the complexity of their research into the social dimensions of the biodiversity crisis; a factor which may have contributed to the dominance of the ecosystem services approach (Opgenoorth et al. 2014). This may also account for the dichotomous approach to knowledge systems (Stenseke and Larigauderie 2018; Vadrot et al. 2018). By presenting different knowledge types and world views in dichotomising and binary ways, the $\mathrm{CF}$ fails to capture the different perspectives, beliefs and values of knowledge holders at finer scales, which is what it set out to achieve (Díaz et al. 2015a). Comparing the Paris CF and the revised edition, the Mother Earth paradigm appears to have been retrospectively palimpsest onto an original CF presented at Paris, with no causal relationships discernible between the elements. It is possible to interpret the retrospective absorption of ILK concepts as an assumption of epistemic primacy (Star and Griesemer 1989). It is difficult, therefore, to see how the CF can serve as a tool to help the IPBES undertake its work requirements, and meet the needs of the diverse range of stakeholders to whom it reports. Maier and Feest (2016) briefly discuss the 'category mistake' made within $\mathrm{CF}$, which they regard as a normative model rather than a scientific one. To this end, they state:

"Western science'" is concerned to discover facts about things in the spatio-temporal world, as well as their descriptive, non-normative properties and relationships. These are not facts about the goodness of certain things, why those things matter, and what we ought to do in a world where these things matter in the ways that they do. In contrast, some part of the "indigenous and local knowledge' to 
which the IPBES authors refer, consists of a body of beliefs about why certain things do matter and what this entails for how people ought to behave with respect to these things (p. 11).

Maier and Feest (2016) thus suggest that it is impossible to reconcile scientific facts with normative claims concerning what is good about such facts.

Furthermore, by presenting both worldviews as fixed and given, the CF fails to provide a way to conceptualise how the challenge of biodiversity loss is constantly evolving. The CF thus 'misses the opportunity to develop a perspective conducive to future developments' (Vohland and Nadim 2015). Thus, we argue, the CF fails to provide interpretive flexibility, and therefore fails to allow diverse actors, operating across a range of spaces and at different times, to use it. As a result, power inequalities arise regarding the representation of local knowledge holders in the interpretation, validation and transfer of their ILK in the IPBES institutional processes. Thus, we must also consider how dissention is managed within IPBES deliberations, including the material or organisational elements that enable or constrain the creation of a shared space. Attention is now turned to these two additional factors, before suggestions are made as to alternative options for the CF.

\subsection{Material and organisational structure}

The material or organisational structure of the $\mathrm{CF}$ also needs to be considered for it to be effective as a boundary object. The intention of the IPBES is to provide a common overarching vision of the relationship between biodiversity, ecosystems and society, in support of its programme of work. This is done through the development of its common CF, designed to serve as a translation device between different knowledge systems (Díaz et al. 2015a, b). Considering the IPBES's global focus, there is also a need to make the findings and data commensurable across spatial scales (Díaz et al. 2015a, b). In order to meet these functional requirements, the $\mathrm{CF}$ needs to enable those that hold different epistemologies, including ILK holders, to work together, by being capable of handling data that is collected and validated in different ways. At the same time, it has to facilitate standardisation, transfer and subsequent application of this data.

Taking the above into account, the IPBES CF will only function effectively as a boundary object if it fulfils the needs and requirements of the range of actors interacting with it. This is achieved through a collaborative process of working together to create and define the boundary space, rather than having one superimposed upon and dictating the process of collaboration. Actors that the IPBES need to include in this process range from policy makers operating at international and state levels, non-government actors, academics engaged in the natural and social sciences, ILK holders, ILK experts and civil society. The CF would need to be sufficiently robust to meet the information needs of this diversity of actors, but also allow ILK to be part of the knowledge base that informs policymaking. In addition, the $\mathrm{CF}$ has to act as a means of mobilising local knowledge and data collection, because of the requirement that the CF be capable of addressing the issue of ecosystem service delivery and biodiversity loss across scale (Díaz et al. 2015b). This will not only ensure that the full range of data sources are made available, but also that the Platform has local relevance, especially given that the biodiversity crisis in the end happens locally and regionally and has also to be addressed at these scales (Opgenoorth and Faith 2013).

The core mission of the IPBES is to act as a science-policy interface. This means that the IPBES has to privilege standardised techniques of assessment and measurement, and in ways that allows it to generate relevant and usable information, and communicate this 
to the policy community (Turnhout et al. 2014). However, there are numerous problems associated with validating and 'standardising' ILK knowledge (Tengö et al. 2014). ILK is often situated within diverse social contexts, where both formal and informal institutions influence knowledge transmission and validation (Whyte et al. 2016; Tengö et al. 2014). In addition, intellectual property rights are often associated with knowledge mobilisation and transfer and these can shape the conditions under which knowledge can be shared (Williams and Hardison 2013). Furthermore, there are concerns that knowledge applied out of its social context and transformed into new information may cause harm to local and indigenous knowledge holders (Tengö et al. 2014). The documentation and abstraction of ILK may provide, for example, a means for groups that are more powerful to appropriate ILK once it has entered the public domain, raising difficult questions surrounding rights to access, ownership and control. Such concerns over access to knowledge about plant resources have plagued the work of the CBD. Meaningful engagement in cross-cultural settings needs to be sensitive to political, often colonial history, which in turn requires trust building between parties (Rathwell et al. 2015). Rather than seek innovative ways in which to address these problems, and find common grounds for collaboration, the process of standardisation adopted by the IPBES lead to a dominant focus on evidence building and data collection methods that are drawn from the natural sciences, with a focus on quantification (Vadrot 2014). Only knowledge that is compatible with (western) scientific knowledge will be deemed usable (Turnhout et al. 2014). This has served to marginalise further alternative views of nature-social relationships, including those held by ILK holders and social scientists, with opportunities lost for more innovative engagements that can underpin the legitimacy of the international governance of biodiversity. Furthermore, the marginalisation of social science participation may contribute to subsequent lack of policy uptake and implementation (Keller et al. 2018).

There are, furthermore, concerns that the $\mathrm{CF}$ is symbolic of a one-way relationship between scientific and 'other' knowledge systems. It is assumed, for instance, that ILK will inform science. Less emphasis seems to be placed upon how the convergence of diverse forms of knowledge may meet the information needs of those in possession of ILK. In addition, there is no attempt to address how contextual knowledge that does not seek to be definitive (Irwin 1995) will benefit from sharing a space with other knowledge types. Yet, whilst the Work Programme of the Platform on indigenous and local knowledge systems includes a mandate to adhere to the 'principles of non-discrimination, inclusiveness, ... [and] seeking prior and informed consent' (UNEP 2016), investigation into the mobilisation of ILK for the IPBES first major report, on pollinators, pollination and food production, revealed that ILK holders were not recognised as equal partners in all aspects (Tengö et al. 2017). In the pollinator report, ILK holders were represented mainly through scientific experts, and these knowledge holders were not directly engaged in the process of negotiation access to, and application of their knowledge, nor were representative organisations of ILK involved in the validation of knowledge that was synthesised in the summary report for policy makers (Tengö et al. 2017). Despite the inclusion of different knowledge holders, scientific expertise dominated. This example serves to illustrate the difficulties encountered by ILK holders in seeking to have their knowledge and the associated respect for integrity and rights, adequately represented. Such practices by the IPBES risks discarding alternative forms of knowledge (Montana 2017).

Soberón and Peterson (2015) argue that 'to deal successfully with the complexity and diversity of local issues, including indigenous knowledge systems, IPBES must recognise a key role of local institutions' (p. 1). Vohland and Nadim (2015): 1 also stress the importance of local contexts. To this end, they state: 
local capacity building and supporting communities to actively participate in research projects dealing with biodiversity are essential for furthering a practical and emancipatory understanding of the relationship between political and economic decisions, the state and functioning of biodiversity and ecosystems, and current and future human wellbeing.

They suggest that the employment of technological innovations harnessed through citizen science methods (Irwin 1995) could make it possible to facilitate data collection at local level, whilst feeding into global context. Whilst this point addresses issues of capacity building and development of methodologies for data collection, it still fails to recognise the contribution that ILK holders can make towards generating knowledge through truly collaborative methods.

\subsection{Recognition of dissention}

It is important to keep in mind that creating a boundary object does not require consensus between actors. When reflecting upon this, it appears that the CF fails to recognise that diverse groups can cooperate without consensus. Instead, the IPBES take a reductionist approach in an attempt to bring diverse viewpoints into agreement. Yet, there appears to be an awareness of this weakness amongst those that developed the CF. For instance, Diaz et al. (2015a) selfcritiqued the $\mathrm{CF}$ as a drastically oversimplified representation of an overwhelmingly diverse natural world. Nevertheless, they justify the merging of concepts from different social worlds within the $\mathrm{CF}$ as central to interdisciplinary and cross-cultural work, and to such an extent that the CF has now become the approved, authoritative and embedded lexicon of IPBES assessment and their other related work.

The CF's failure to recognise that groups cooperate without consensus means that it fails to be correctly employed as a boundary object. As such, it is unlikely that it will be able to facilitate the sharing of space amongst diverse actors. This is perhaps where the CF suffers its greatest fall: it portrays that it is necessary to merge heterogeneous concepts and viewpoints to advance knowledge. However, seeking direct translation of scientific concepts into terms understood by all is problematic. Rather than presenting the CF as a unified Rosetta Stone (Díaz et al. 2015a), the IPBES could instead seek to stimulate both autonomy and communication between worlds (Star and Griesemer 1989). Thus, rather than assuming dissention and uncertainty away, the CF could make these elements explicit. As Star and Griesemer (1989) state: 'When participants in the intersecting worlds create representations together...this resolution does not mean consensus. Rather, representations, or inscriptions, contain at every stage the traces of multiple viewpoints, translations and incomplete battles' (p. 413). As such, the IPBES has lost the opportunity to demonstrate how decisions can be made under conditions of knowledge uncertainty and systems divergence. There are future opportunities for the IPBES to embrace a more pluralistic perspective, which would involve recognising dissention as an inevitable part of processes that bring knowledge systems together. As such, it is crucial that a constructive framing for dissenting voices is reinforced, not only through providing space for dissenting voices. but by ensuring that all stakeholders inputs are reflected within process outcomes. 


\section{A boundary object? beyond translation of concepts}

The proposal that the CF be viewed as a boundary object is an appealing one. It speaks to the concerns of involving diverse actors in providing the scientific evidence needed to underpin policy to tackle the biodiversity crisis. Such a view resonates with instrumentalist scholarship on boundary work, which frames coproduction as a crucial link between knowledge and action (Wyborn 2015). From a normative perspective, alternative ways of addressing conflicting worldviews could see unacceptable 'imperialist imposition of representation, coercion, silencing and fragmentation' (Star and Griesemer 1989: 413). Yet, the above discussion casts doubt on whether the CF can, in its current state, function as a boundary object. There are concerns over the prioritisation of western science, incorporation of alternative worldviews as 'other', and the failure to develop links between them that equalises their respective values. Central to this argument is the CF's overt focus upon translations of concepts. Díaz et al. (2015a) regard the CF as a Rosetta Stone, representing nature's benefits to people. Yet, we can question whether conceptual translation is enough to facilitate collaborative work across knowledge systems. Indeed, Star (2010) cites the Rosetta Stone as an example of the interpretive flexibility of words. Yet, she also argues that organisational factors also need to be considered. Here it is crucial to think about the second characteristic of a boundary object, namely that it enables the information needs, and the work arrangements of diverse groups to be taken into account.

Ultimately, a boundary object needs to be flexible to be of use to a range of actors. Star (2010) observes that over time, people (often administrators or regulatory agencies) try to control the 'tacking back-and-forth', and to standardise and make equivalent both the ill-structured and the well-structured aspects of a particular boundary object (p. 614). This can be seen in the development of the CF. Scientists began by attempting to include the voices of all actors, but over time Western science has come to dominate. As a result, tensions remain in relation to the IPBES' desire to reconcile its goals of open and collaborative engagement of diverse actors, on the one hand, and on the other, the demands for structure and standardisation set by the dominating scientific framework (Löfmarck and Lidskog 2017). The diversity of actors' perspectives is not recognised within the CF. Yet, for the CF to act as an effective boundary object, it must allow actors to maintain their autonomy. This is particularly important in the mobilisation of ILK because, as we have stressed, this specific strand of knowledge is not easily shared, and attention must be paid to the complexities associated with the socio-cultural and political institutional contexts surrounding ILK and its use. Furthermore, the IPBES' central focus on consensus during decision-making negates wider contested and conflict-laden issues, increasing the risk that ILK will become scientised and that only the forms of knowledge that are compatible with western science will be utilised (Tengö et al. 2014; Löfmarck and Lidskog 2017).

One option for complying with the characteristics of a boundary object would be to restructure the $\mathrm{CF}$. This restructuring needs to begin by acknowledging the multiple passage points that diverse actors may pass through to work together. The CF could also become less structured in the way in which it delineates specific normative concepts. For example, specific reference to different ways of viewing nature's benefits to people could be removed. Such specifics are unnecessary when constructing an effective boundary object. To this end, Star (2010) observed that a boundary object, such as a map, does not need to be accurate to be useful. Rather, it can serve as a basis for conversation, data sharing, or for pointing to things, without actually demarcating any real territory. What is important here is that the 'mediation qualities of that map are attributable to the fact that it 
'sat in the middle' between different groups, very ill-structured or sketchy in the common usage' (p. 609). To serve as a boundary object, the IPBES CF would need to represent such a shared space and become something towards which diverse groups act. Achieving boundary object status is important to the IPBES for, whilst they don't use the specific word, there is nonetheless the desire that the CF provides a 'shared language', whose role is to 'to structure the syntheses that will inform policy'... 'and to provide common ground, to facilitate cross-disciplinary and cross-cultural understanding and interoperability, and to identify options for action'... 'Within this context, the CF has been considered a 'Rosetta Stone' to enable 'translating' basic concepts and facilitating communication, and assisting the formulation of fundamental understanding that is transparent, salient, credible and legitimate to all parties involved' (Díaz et al. 2015a). As a Rosetta Stone, the CF is 'explicitly embracing different disciplines and knowledge systems (including indigenous and local knowledge) in the coconstruction of assessments' (Díaz et al. 2015b).

Recognising that all knowledge is unavoidably situated (Jasanoff 2004) would allow the IPBES to move away from focusing upon the standardisation of divergent forms of knowledge and trying to translate across knowledge systems. However, alternative methodologies for generating and mobilising usable knowledge from across different epistemic traditions is within its infancy. Nevertheless, several researchers have provided guidance on how collaborations with diverse knowledge holders can be facilitated in international sciencepolicy interface. Tengö et al. (2014) propose an approach that recognises the incommensurability of different knowledge systems. This approach stresses the importance of complementarity, and the validation of knowledge within rather than across knowledge systems. This may enable the IPBES to avoid the pitfalls of combining incompatible knowledge systems, provide more meaningful and inclusive engagement with diverse knowledge holders, and overcome concerns that its practices assert epistemic primacy.

\section{Conclusion}

This article has explored the claim that the IPBES CF acts as a boundary object that aligns diverse actors (Borie and Hulme 2015). It has contested this notion. In particular, the authors have highlighted how the $\mathrm{CF}$ focuses explicitly on providing interpretive flexibility alone. In doing so, the CF ignores the two other elements of effective boundary objects. Boundary objects, as Star (2010) notes, must not only focus upon the translation of linguistic differences. They need also to provide a shared space for collaboration and room for dissention, both of which the IPBES CF ignores. Difficulties in meeting these requirements of a boundary object serve to illuminate the challenges of boundary crossing work.

This paper has also explored how the CF might be redesigned, accepting that consensus is not a necessary condition for the generation of new knowledge. This critical issue will need to be addressed if the CF is to retain its relevance to multiple stakeholder groups. As Star and Griesemer (1989) note in relation to the development of scientific work, there is a need to 'go beyond mere trading across unjoined world boundaries' (p. 413). It is also crucial to ensure that they 'are not simply the imposition of one world's vision on the rest, if they are, they are sure to fail' (p. 414). The core tool structuring the assessment work of the IPBES needs to accept the validity of all its knowledge holders. The CF represents the worldview of the IPBES (Vohland and Nadim 2015) and has been criticised for failing to find ways of dealing with contrasting rationalists, diverging ontologies and different criteria for knowledge validation (Löfmarck and Lidskog 2017). Unless it moves beyond its 
existing representation to address fully issues of legitimacy and inclusion, the CF must be viewed not as an analytical tool or heuristic device, but as a normative model that seeks to assert the epistemological primacy of a single worldview. Star and Griesemer (1989) state that the fundamental tension in science concerns the question: 'how can findings which incorporate radically different meanings become coherent?' (p. 392). The development of the $\mathrm{CF}$ represents a direct attempt to address this tension. This paper unveils that the CF does, to some extent, bridge divides that exist between social worlds, a key component of a boundary object. It thus enables diverse groups to interpret it. Yet for the CF to fulfil its role as a boundary object it would need to embrace lack of consensus amongst diverse actors. This appeal to the IPBES resonates with similar calls that the Platform do away with the 'integration imperative' and live up to the challenge of cultural relativity (Obermeister 2017).

Greater focus on all three elements of a boundary object will enable the IPBES to better realise both its instrumental and normative objectives. We thus go beyond merely presenting critiques of the work of the IPBES, pointing to how it can improve from both instrumental and normative perspectives. There are a host of moral, political and practical reasons to bridge diverse knowledge systems in the context of global governance (Rathwell et al. 2015). From an instrumental and practical lens, utilising the CF as a full boundary object will help ensure the translation and uptake of a more complete array of knowledge that can, in turn, support much needed biodiversity management. Taking into consideration, diverse perspectives on nature and different epistemologies are critical for balancing power inequalities and meeting the wider normative objectives of the IPBES. Bridging different knowledge systems requires more than merely cocreating, but it must also address the normative issues of how, where and why knowledge is used to support action (Wyborn 2015). To develop this more critical and reflexive approach, there is a need to recognise that the gap between science, policy and practice is actually a space of communication and negotiation (Wyborn 2015). In engaging with that boundary, competing interest, values and perspectives come to the fore, which coalesce to shape the governance of global environmental change. The IPBES CF could be argued to have evolved out of dissention, where challenges to the dominant western scientific paradigm have led to new efforts to embrace different worldviews and this has raised important ethical concerns, revealing the current and future grounds on which the CF is currently being debated and applied. In fulfilling its normative agenda, power imbalances need to be adjusted so that the IPBES can enable diverse voices to be reflected in its boundary work. By demonstrating the need to embrace the full characteristics of a boundary object we have suggested ways that the IPBES can manage social processes to support better knowledge coproduction and translation.

Open Access This article is distributed under the terms of the Creative Commons Attribution 4.0 International License (http://creativecommons.org/licenses/by/4.0/), which permits unrestricted use, distribution, and reproduction in any medium, provided you give appropriate credit to the original author(s) and the source, provide a link to the Creative Commons license, and indicate if changes were made.

\section{References}

Abson, D. J., von Wehrden, H., Baumgartner, S., Fischer, J., Hanspach, J., Hardtle, W., et al. (2014). Ecosystem services as a boundary object for sustainability. Ecological Economics, 103, 29-37.

Baggio, J. A., Brown, K., \& Hellebrandt, D. (2015). Boundary object or bridging concept? A citation network analysis of resilience. Ecology and Society, 20(2), 2. 
Baker, S. (2016). Sustainable development. New York: Routledge.

Baker, S. (2018). What is biodiversity associated TK from the perspective of the UN intergovernmental science-policy platform on biodiversity and ecosystem services (IPBES), presented at the international conference, traditional knowledge in the international governance of biogenetic resources, Switzerland January 2018, organized by the Intitut d'Etudes politiques, historiques et internationals, University of Lausanne (in press).

Baker, S., \& Chapin, F. I. I. I. (2018). Going beyond "it depends:" The role of context in shaping participation in natural resource management. Ecology and Society, 23(1), 20. https://doi.org/10.5751/ ES-09868-230120.

Beck, S., Borie, M., Chilvers, J., Esguerra, A., Heubach, K., Hulme, M., et al. (2014). Towards a reflexive turn in the governance of global environmental expertise. The cases of the IPCC and the IPBES. GAIA-Ecological Perspectives for Science and Society, 23, 80-87.

Borie, M., \& Hulme, M. (2015). Framing global biodiversity: IPBES between mother earth and ecosystem services. Environmental Science \& Policy, 54, 487-496.

Brand, F., \& Jax, K. (2007). Focusing the meaning (s) of resilience: Resilience as a descriptive concept and a boundary object. Ecology and Society, 12, 23-38.

Bridgewater, P. (2017). The intergovernmental platform for biodiversity and ecosystem services (IPBES)— A role for heritage? International Journal of Heritage Studies, 23, 65-73.

Cash, D. W., Borck, J. C., \& Patt, A. G. (2006). Countering the loading-dock approach to linking science and decision making: Comparative analysis of El Niño/southern oscillation (ENSO) forecasting systems. Science, Technology and Human Values, 31, 465-494.

Cash, D. W., Clark, W. C., Alcock, F., Dickson, N. M., Eckley, N., Guston, D. H., et al. (2003). Knowledge systems for sustainable development. Proceedings of the National Academy of Sciences, 100, 8086-8091.

Castree, N. (1995). The nature of produced nature: Materiality and knowledge construction in Marxism. Antipode, 27, 12-48.

Cornell, S., Berkoutet, F., Tuinstracal, W., Tabara, J. D., Jager, J., Bertde, I. C., et al. (2013). Opening up knowledge systems for better responses to global environmental change. Environmental Science \& Policy, 28, 60-70.

Díaz, S., Demissew, S., Carabias, J., Joly, C., Lonsdale, M., Ash, N., et al. (2015a). The IPBES conceptual framework-Connecting nature and people. Current Opinion in Environmental Sustainability, 14, $1-16$.

Díaz, S., Demissew, S., Joly, C., Lonsdale, W. M., \& Larigauderie, A. (2015b). A Rosetta Stone for nature's benefits to people. PLoS Biology, 13, e1002040.

Gieryn, T. F. (1983). Boundary-work and the demarcation of science from non-science: Strains and interests in professional ideologies of scientists. American Sociological Review, 48, 781-795.

Guston, D. H. (2001). Boundary organizations in environmental policy and science: An introduction. Thousand Oaks, CA: Sage Publications Sage CA.

Heubach, K., \& Lambini, C. K. (2018). Distribution and selection of experts in the intergovernmental science-policy platform on biodiversity and ecosystem services (IPBES): The case of the regional assessment for Africa. Innovation: The European Journal of Social Science Research, 31(sup1), S61-S77. https://doi.org/10.1080/13511610.2017.1377601.

IISD Reporting Services. (2013). Summary of the first plenary meeting of the intergovernmental platform on biodiversity and ecosystem services (Vol. 31, no. 06), January 21-26, 2013 (IISD, Tuesday, 29 January). http://enb.iisd.org/vol31/enb3106e.html. Accessed 24 May 2018.

IPBES. (2012). Functions, operating principles and institutional arrangements of the intergovernmental science-policy platform on biodiversity and ecosystem services adopted by the second session of the plenary meeting to determine the modalities and institutional arrangements for IPBES, held from April 16-21, 2012 in Panama city, Panama. https://www.ipbes.net/sites/default/files/downloads/Funct ions\%20operating\%20principles\%20and\%20institutional\%20arrangements\%20of\%20IPBES_2012. pdf. Accessed 24 May 2018.

IPBES. (2013a). Conceptual framework for the intergovernmental science-policy platform on biodiversity and ecosystem services (IPBES, Decision IPBES-2/4). https://www.ipbes.net/sites/default/files/downl oads/Decision\%20IPBES_2_4.pdf. Accessed 24 May 2018.

IPBES. (2013b). Outcome of an informal expert workshop on main issues relating to the development of a conceptual framework for the intergovernmental science-policy platform on biodiversity and ecosystem services. https://www.ipbes.net/sites/default/files/downloads/pdf/IPBES_MEP_1_8.pdf. Accessed 24 May 2018.

IPBES. (2014). Plenary of the intergovernmental science-policy platform on biodiversity and ecosystem services third session Bonn, Germany, January 12-17, 2015 'Rules and procedures for the operations 
of the Platform: Nomination and selection of members of the multidisciplinary expert panel: Guidance document on the nomination and selection process for members of the multidisciplinary expert panel and lessons learned from the experience of the interim Panel', IPBES/3/INF/16. Available online at https://www.ipbes.net/system/tdf/downloads/IPBES_3_INF_16.pdf?file=1\&type=node \&id=13125. Accessed 24 May 2018.

Irwin, A. (1995). Citizen science: A study of people, expertise and sustainable development. New York: Psychology Press.

Jasanoff, S. (2004). States of knowledge: The co-production of science and the social order. Abingdon: Routledge.

Jetzkowitz, J., Van Koppen, C. S. A., Lidskog, R., Ott, K., Voget-kleschin, L., \& Wong, C. M. L. (2017). The significance of meaning. Why IPBES Needs the Social Sciences and Humanities., 31(sup1), S38-S60.

Johnson, J. T., Howitt, R., Cajete, G., Berkes, F., Louis, R. P., \& Kliskey, A. (2016). Weaving indigenous and sustainability sciences to diversify our methods. Sustainability Science, 11(1), 1-11.

Katsumi, M., \& Grüninger, M. (2016). What is ontology reuse? In W. K. R. Ferrario (Ed.), Formal ontology in information systems. Amsterdam: IOS Press.

Keller, R., Keune, H., \& Maynard, S. (2018). Where do IPBES delegates in Europe see challenges, needs, gaps and opportunities in policy uptake of "Nature's contributions to people"? Innovation: The European Journal of Social Science Research, 31(sup1), S116-S124. https://doi.org/10.1080/13511 610.2017.1361814.

Koetz, T., Farrell, K. N., \& Bridgewater, P. (2012). Building better science-policy interfaces for international environmental governance: Assessing potential within the intergovernmental platform for biodiversity and ecosystem services. International Environmental Agreements: Politics, Law and Economics, $12,1-21$.

Löfmarck, E., \& Lidskog, R. (2017). Bumping against the boundary: IPBES and the knowledge divide. Environmental Science \& Policy, 69, 22-28.

Maclean, K. (2015). Crossing cultural boundaries: Integrating Indigenous water knowledge into water governance through co-research in the Queensland wet tropics, Australia. Geoforum, 59, 142-152.

Maier, D., \& Feest, A. (2016). The IPBES conceptual framework: An unhelpful start. Journal of Agricultural and Environmental Ethics, 29, 327-347.

Miller, C., \& Erickson, P. (2006). The politics of bridging scales and epistemologies: science and democracy in global environmental governance. Bridging scales and knowledge systems: concepts and applications in ecosystem assesments. Washington: Islan.

Montana, J. (2017). Accommodating consensus and diversity in environmental knowledge production: Achieving closure through typologies in IPBES. Environmental Science \& Policy, 68, 20-27.

Natcher, D. C., Davis, S., \& Hickey, C. G. (2005). Co-management: Managing relationships, not resources. Human Organization, 64, 240-250.

Obermeister, N. (2017). From dichotomy to duality: Addressing interdisciplinary epistemological barriers to inclusive knowledge governance in global environmental assessments. Environmental Science \& Policy, 68, 80-86.

Opgenoorth, L., \& Faith, D. P. (2013). The intergovernmental science-policy platform on biodiversity and ecosystem services (IPBES), up and walking. Frontiers of Biogeography, 5(4), 207-211.

Opgenoorth, L., Hotes, S., \& Mooney, H. (2014). IPBES: Biodiversity panel should play by rules. Nature, $506,159$.

Rathwell, K. J., Armitage, D., \& Berkes, F. (2015). Bridging knowledge systems to enhance governance of environmental commons: A typology of settings. International Journal of the Commons, 9(2), $851-880$.

Reimerson, E. (2013). Between nature and culture: Exploring space for indigenous agency in the convention on biological diversity. Environmental Politics, 22(6), 992-1009.

Rödder, S. (2017). The climate of science-art and the art-science of the climate: Meeting points, boundary objects and boundary work. Minerva, 55, 93-116.

Schröter, M., Zanden, E. H., Oudenhoven, A. P., Remme, R. P., Serna-Chavez, H. M., Groot, R. S., et al. (2014). Ecosystem services as a contested concept: A synthesis of critique and counter-arguments. Conservation Letters, 7, 514-523.

Soberón, J., \& Peterson, A. T. (2015). Biodiversity governance: A tower of Babel of scales and cultures. PLoS Biology, 13, e1002108.

Star, S. L. (2010). This is not a boundary object: Reflections on the origin of a concept. Science, Technology and Human Values, 35, 601-617.

Star, S. L., \& Griesemer, J. R. (1989). Institutional ecology, translations' and boundary objects: Amateurs and professionals in Berkeley's Museum of Vertebrate zoology. Social Studies of Science, 19, 387-420. 
Steger, C., Hirsch, S., Evers, C., Branoff, B., Petrova, M., Nielsen-Pincus, M., et al. (2018). Ecosystem services as boundary objects for transdisciplinary collaboration. Ecological Economics, 143, 153-160.

Stenseke, M., \& Larigauderie, A. (2018). The role, importance and challenges of social sciences and humanities in the work of the intergovernmental science-policy platform on biodiversity and ecosystem services (IPBES). Innovation: The European Journal of Social Science Research, 31(sup1), S10S14. https://doi.org/10.1080/13511610.2017.1398076.

Tengö, M., Brondizio, E. S., Elmqvist, T., Malmer, P., \& Spierenburg, M. (2014). Connecting diverse knowledge systems for enhanced ecosystem governance: The multiple evidence base approach. Ambio, 43, 579-591.

Tengö, M., Hill, R., Malmer, P., Raymond, C. M., Spierenburg, M., Danielsen, F., et al. (2017). Weaving knowledge systems in IPBES, CBD and beyond-Lessons learned for sustainability. Current Opinion in Environmental Sustainability, 26, 17-25.

Thaman, R., Lyver, P., Mpande, R., Perez, E., Cariño, J., \& Takeuchi, K. (2013). The contribution of indigenous and local knowledge systems to IPBES: Building synergies with science, IPBES expert meeting report. Paris: UNESCO/UNU.

Timpte, M., Montana, J., Reuter, K., Borie, M., \& Apkes, J. (2018). Engaging diverse experts in a global environmental assessment: Participation in the first work programme of IPBES and opportunities for improvement. Innovation: The European Journal of Social Science Research, 31(sup1), S15-S37. https://doi.org/10.1080/13511610.2017.1383149.

Trompette, P., \& Vinck, D. (2009). Revisiting the notion of boundary object. Revue d'anthropologie des Connaissances, 3(1), 3-25.

Turnbull, D. (2000). Masons, tricksters and cartographers: Comparative studies in the sociology of scientific and indigenous knowledge. Abingdon: Taylor and Francis.

Turnhout, E., Bloomfield, B., Hulme, M., Vogel, J., \& Wynne, B. (2012). Conservation policy: Listen to the voices of experience. Nature, 488, 454-455.

Turnhout, E., Neves, K., \& de Lijster, E. (2014). 'Measurementality'in biodiversity governance: knowledge, transparency, and the intergovernmental science-policy platform on biodiversity and ecosystem services (IPBES). Environment and Planning A, 46, 581-597.

UNEP. (2010). Report of the third ad hoc intergovernmental and multi-stakeholder meeting on an intergovernmental science-policy platform on biodiversity and ecosystem services Busan, Republic of Korea, June 7-11, 2010, UNEP/IPBES/3/3. Available online at https://www.ipbes.net/sites/default/files/downl oads/doc/UNEP_IPBES_3_3_EN_0.doc. Accessed 24 May 2018.

UNEP. (2012). Plenary of the intergovernmental science-policy platform on biodiversity and ecosystem services first session Bonn, Germany, January 21-26, 2013, Item 5 of the provisional agenda: Initial work programme of the platform outcome of an informal expert workshop on main issues relating to the development of a conceptual framework for the Intergovernmental Science-Policy Platform on Biodiversity and Ecosystem Services, Note by the secretariat, Annex, (UNEP, IPBES/1/INF/9).

UNEP. (2016). Plenary of the intergovernmental science-policy platform on biodiversity and ecosystem services fourth session Kuala Lumpur, February 22-28, 2016y, January 21-26, 2013, item 5 of the provisional agenda: Work programme of the plaftorm: Work on indigenous and local knowledge system for the intergovernmental science-policy platform on biodiversity and ecosystem services, Note by the secretariat, Annex (IPBES, IPBES/4/7). Available: http://www.ipbes.net/sites/default/files/downloads/ IPBES-4-7_EN.pdf. Accessed 24 May 2018.

UNESCO. (2013). The contribution of indigenous and local knowledge systems to IPBES: Building synergies with science, IPBES, expert meeting report, June 9-11, 2013, Tokyo. Available on line at: http:// unesdoc.unesco.org/images/0022/002252/225242E.pdf. Accessed 24 May 2018.

Vadrot, A. B. M. (2014). The epistemic and strategic dimension of the establishment of the IPBES: "Epistemic selectivities" at work. Innovation: The European Journal of Social Science Research, 27(4), 361-378. https://doi.org/10.1080/13511610.2014.962014.

Vadrot, A. B. M. (2016). The birth of a science-policy interface: The history of the IPBES. In M. A. P. D. Hrabanski (Ed.), The intergovernmental platform on biodiversity and ecosystem services (IPBES): Meeting the challenge of biodiversity conservation and governance. London: Routledge.

Vadrot, A. B. M., Rankovic, A., Lapeyre, R., Aubert, P.-M., \& Laurans, Y. (2018). Why are social sciences and humanities needed in the works of IPBES? A systematic review of the literature. Innovation: The European Journal of Social Science Research, 31(sup1), S78-S100. https://doi.org/10.1080/13511 610.2018 .1443799$.

Vohland, K., Mlambo, M. C., Horta, L. D., Jonsson, B., Paulsch, A., \& Martinez, S. I. (2011). How to ensure a credible and efficient IPBES? Environmental Science \& Policy, 14, 1188-1194.

Vohland, K., \& Nadim, T. (2015). Ensuring the success of IPBES: Between interface, market place and parliament. Philosophical Transactions of the Royal Society B, 370, 20140012. 
Wenger, E. (1998). Communities of practice: Learning, meaning, and identity. Cambridge, UK: Cambridge University Press.

Whyte, K. P., Brewer, J. P., \& Johnson, J. T. (2016). Weaving Indigenous science, protocols and sustainability science. Sustainability Science, 11, 25-32.

Williams, T., \& Hardison, P. (2013). Culture, law, risk and governance: contexts of traditional knowledge in climate change adaptation. Climatic Change, 120, 531-544.

Wyborn, C. (2015). Connectivity conservation: Boundary objects, science narratives and the co-production of science and practice. Environmental Science \& Policy. https://doi.org/10.1016/j.envsci.2015.04.019. 